\title{
Alicia en su país verde: política, politización e institucionalización de los feminismos
}

Alice in Her Green Country: Politics, Politization and Institutionalization of

Feminisms

Alice em seu país verde: política, politização e estabelecimento de los

feminismos

María Mónica Sosa Vásquez' (iD 0000-0002-3347-796X

'Facultad Latinoamericana de Ciencias Sociales, Buenos Aires, Argentina.

C1050AAN - antropologia@flacso.org.ar

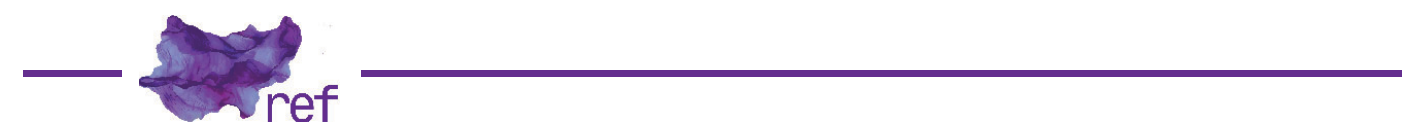

ANGILLETTA, Florencia.

Zona de promesas. Cinco discusiones fundamentales entre los feminismos y la política.

Buenos Aires: Capital Intelectual, 2021. 189p.

"'Gender' is about asking historical questions; (Joan SCOTT, 2008, p. 1423).

Jacques Lacan y Simone de Beauvoir sostuvieron que La Mujer no existía. Para Julia Kristeva (1981, p. 30), el psicoanalista se refería a su inexistencia en tanto unidad mítica, no tan diferente de "una mujer no nace, se hace" (DE BEAUVOIR, 2005 [1949]), tesis amplia y profundamente retomada por feministas en el mundo. Podemos trasladar esta idea a que el Feminismo tampoco existe, cuyo "origen" suele ser situado en la Revolución Francesa. Esta ha sido una suerte de primera piedra en la construcción de - en términos de Griselda Pollock (2010) - un museo virtual feminista en donde la hermana ilustrada, bastarda decapitada, dedo en las llagas de la izquierda y olvido del progresismo ha elaborado sus propios documentos culturales. Zona de promesas. Cinco discusiones fundamentales entre los feminismos y la política (Florencia ANGILLETTA, 2021) es una revisión de estos documentos sobre un presente denominado cuarta ola feminista', la última de la cronología de las olas².

En la Argentina, la primera convocatoria del Ni Una Menos (NUM) inauguró una serie de acontecimientos que han sido englobados con este término, desde y sobre el cual ha

\footnotetext{
'Circunscrita a esta narrativa, la llamada "Marea Verde" convergió con otros "estallidos" occidentales en torno a demandas feministas de gran resonancia como el Me Too y su respuesta francesa LE MONDE. "Nous défendons une liberté d'importuner, indispensable á la liberté sexuelle". Le Monde. París, France. 5 de enero de 2018. Disponible em: https://www.lemonde.fr/idees/article/2018/01/09/nous-defendons-une-liberte-d-importuner-indispensable-a-laliberte-sexuelle 5239134 3232.html. Consultado el: 15 enero 2019.

${ }^{2}$ Una temporalidad que constituye el recorrido por excelencia de este museo virtual casi siempre planteado desde los acontecimientos de su epicentro occidental, Estados Unidos y algunos países europeos.
} 
habido una prolífica producción intelectual, en la que me permito incluir esta obra. Si bien, en el país sudamericano, el feminismo existió propiamente desde finales del siglo XIX, es difícil pensar otro momento que pueda equiparársele, puesto que, por primera vez, se ha convertido en "un significante disponible - y en disputa - de modo cada vez más masivo y masificado" (ANGILLETTA, 2021 , p. 19). Fuente de sentidos y escenario de ríspidos y fecundos debates, una de las particularidades de aquella casa de las diferencias ha sido sustituir feminismo por feminismos. La autora reconoce que, aunque su mediatización expande sus condiciones de posibilidad, ésta va de la mano con el reto de su fetichización (ANGILLETTA, 2021, p. 77).

Enunciada desde el título, la separación entre feminismos y política es la unión de dos mundos que, en su capa más superficial, son distintos, pero que luego de recordar que "lo personal es político" - una de las enseñanzas más potentes del feminismo radical estadunidense de los setenta - no lo son. Sin embargo, Florencia Angilleta (2021) no se detiene en este statement - que, ciertamente, ha permitido conceptualizar las violencias de género - sino que explora sus matices, en donde los imperativos por develar la intimidad convergen con los escraches, ante el "si todo es político, nada es político", conforme a nociones que simpatizan con las ideas de la antropóloga Marta Lamas $(2018,2021)$ y Alexandra Kohan $(2019 a, 2019 b, 2020)$, autoras a quienes volverá una y otra vez.

En este panorama inédito, Zona de promesas (2021) es una expresión y una síntesis de conversaciones glocales con una voz teñida de argentinidad y, sobre todo, de porteñidad; tonos palpables en las múltiples referencias, metáforas y preocupaciones en torno al rock nacional, el peronismo, la literatura argentina y eventos históricos. Estos aspectos dan cuenta del transcurso afectivo en la transmisión generacional. He ahí la importancia que la autora le concede a la época y a la generación, términos que le permiten explorar los pequeños y grandes cambios que han atravesado - y atraviesan - a la sociedad argentina, en la cual los feminismos han desbordado a sus históricas audiencias y también a quienes han conformado su histórico sujeto político: las mujeres [cis]. La primera cuestión corresponde a la expansión de la "alfabetización feminista" y la segunda a la propuesta del lenguaje inclusivo.

Este tipo de alfabetización puede pensarse a partir de María Eva Duarte de Perón, quien no sólo no se concebía feminista, sino que se oponía a quienes sí; entre ellas, la médica socialista Alicia Mureau de Justo y la directora de la Revista Sur, Victoria Ocampo. A diferencia de estas feministas, Eva no creció ni estuvo rodeada de una "biblioteca ni círculos letrados" (ANGILLETTA, 2021, p. 151). No obstante, hoy presenciamos una relectura que interpreta el peso de sus acciones y discursos políticos, como ilustra la caracterización de esta figura como "profeminista empírica, práctica" realizada por Dora Barrancos (2019, p. 28). Para Angilletta (2021, p. 151), la discusión de los "usos de Eva" es una interna de la "patria feminista".

En tanto práctica deslegitimadora, Angilletta se detiene en la medición realizada por las feministas entre sí y de quienes no se perciben como tal, a la usanza de "La mujer que le tira con la biblioteca a otra mujer parece reescribir, en el francés sarmentino, 'bárbaras, las ideas feministas no se tocan'" (ANGILLETTA, 2021, p. 79). Con base en las lecturas de Eva Illouz, Carlina Justo von Lurzer y Carolina Spataro, por mencionar algunas, la autora coloca en tela de juicio aquellas posiciones feministas doctas que circunscriben a la cultura de masas como tontas y víctimas.

La segunda cuestión mencionada hace un par de párrafos: el lenguaje inclusivo. Su cuestionamiento es dirigido hacia qué tanto puede incluir la "e", empleada para referirse a las personas no binarias en el castellano. Luego de sugerir una conversación entre Santiago Kalinowski y Beatriz (2019) sobre las aristas de la lengua, la autora nos pregunta "¿Cómo volver inclusivos a las y los sujetos de enunciación de ese lenguaje - porque plebeyizados después de y no antes, y no es igual para quienes ni siquiera tienen una lengua pública?" (ANGILLETTA, 2021, p. 76).

Sobre esta línea, Angilletta critica la institucionalización de una lectura sobre el género, pero también sobre el feminismo, por eso es relevante el hincapié en su pluralidad. Un fragmento destacable es su breve impresión al leer un afiche en un museo del Distrito Federal (México) que decía "¿Qué historia nos cuenta este cuadro sobre desigualdad? ¿Cómo podemos ver esto desde perspectivas de género?" (ANGILLETTA, 2021, p. 59). Aquel tono indicativo que parecía un avance de los feminismos, levanta un manto de sospecha, pues previene ante la instalación de una pedagogía feminista, en tanto implica un - el - "modo correcto" de pensar desde esta posición, como si sólo un punto de vista feminista fuese posible y éste se agotara en sí mismo. De modo que, a partir de la premisa "cualquier sistema de lectura es a la vez una máquina para descubrir y una máquina para ocultar" (SARLO, 1983, p. 807), la autora alumbra algunas oscuridades del sistema de lectura representado en aquel afiche.

Entonces plantea si '¿Podemos hacer caer el 'patriarcado' o solo gestionamos su fracaso?" (ANGILLETTA, 2021, p. 27) como una preocupación transversal a la obra que cobra fuerza con el pasaje del museo, que - a la par - conduce a los jaques en los que determinadas intervenciones feministas han colocado al consumo de ciertos productos culturales, que conduce a las intersecciones entre arte-moral y artista-obra. La tensión generada por este par de estribos dirige hacia la llamada "cultura de la cancelación" que - para Angilletta - construye 
un "museo 'de lo que no'” (ANGILLETTA, 2021, p. 65), con lo que se pretende abolir conflictos como si se pudiese pasar una brocha punitivista sobre ellos y, de nuevo, nos previene de puede pasar encima de nosotras:

El moralismo ante los demás - que ubica como jueces o policías, y no desde la crítica literaria es una flecha que también apunta sobre nuestras vidas - ¿habrá "buenas" y "malas" feministas cuyas obras sean juzgadas con esas varas? -. Lo opuesto al moralismo no es el relativismo: queda el lugar para proponer una ética. El arte no 'refleja' la sociedad, el artista no se 'expresa' en su obra y la crítica no es la 'policía' del arte. (ANGILLETTA, 2021, p. 66).

Aunque las "cancelaciones" - o debates sobre las mismas - sobre ciertos objetos culturales como Lolita (Vladimir NABOKOV, 2016 [1955]), Blancanieves y los siete enanos (David HAND 1937) y Matate, Amor (Ariana HARWICZ, 2012) o las películas de Woody Allen, el "linchamiento" y "escrache" son estrategias empleadas para la denuncia de abusos que no iniciaron con los feminismos $^{3}$ ni sólo provienen de éstos (ANGILLETTA, 2021, p. 112). Desde su perspectiva, el escrache y su mediatización se presentan como "una forma de visibilizar una voz de quienes de otra forma no la tendrían" (ANGILLETTA, 2021, p. 113), pero es complicado sentenciar "escrache sí" o "escrache no" sin evaluar los matices de cada situación, en los que la diferencia entre poder y abuso de poder adquieren sus particularidades, también abordado en $Y \sin$ Embargo el Amor, libro en el que Alexandra Kohan (2020) señala la imposibilidad de legislar sobre el deseo y la protocolización de las relaciones a partir de términos como el dúo "amor sano/amor tóxico"; "amor libre"; y "responsabilidad afectiva", entre otros.

Consternada por los efectos del punitivismo, Angilleta (2021, p. 115) habla sobre cómo la "industria de la victimización" fabrica distintas víctimas. Las "buenas", por un lado, son aquellas a quienes se les suprime la seducción, como ha sido referirse a ellas cual "nenas" sin importar que no se trate de niñas. Esta denominación pretende, a través de una infantilización, ablandar el terreno de la figura de la víctima ideal y nos pregunta "¿Por qué, para ser escuchadas y que haya justicia, las mujeres y disidencias sexuales tienen que vestirse de luto o infantilizarse?" (ANGILLETTA, 2021, p. 115). Por otro lado, "las malas" son aquellas que - con escotes, animal print y salidas a antros - "contaminan" lo que se espera de las víctimas.

Pero "¿Por qué las mujeres y disidencias sexuales [sólo] accedemos a la palabra pública a partir de una narrativa que nos ubica como víctimas?". Si una mujer presenta un libro de poesía, asisten decenas de personas; si una mujer denuncia a un poeta, firman cientos" (ANGILLETTA, 2021 , p. 116). Otra cuestión fundamental es que, pese a que cada vez atestiguamos una mayor cantidad de casos, no todas las personas que denuncian cuentan con la misma plataforma para enunciar ni ser escuchadas ni tampoco de estar acompañadas en un proceso complejo.

A diferencia de México, en donde los feminismos han sido la oposición más radical al Estado - encabezado por el presidente Andrés Manuel López Obrador, procedente del partido MORENA -, el gobierno del Frente de Todos - con Alberto Fernández (2019 - presente) en la presidencia ha incorporado una cuota de estos feminismos. Aunado a la despenalización del aborto a finales de diciembre de 2020 y la promulgación del cupo laboral travesti-trans en julio de 2021, una de sus edificaciones más destacadas ha sido el Ministerio de Mujeres, Géneros y Diversidad, antes llamado Consejo Nacional de la Mujer. Para la autora, el cambio de nombre es un "síntoma de las discusiones de las lenguas feministas" (ANGILLETTA, 2021, p. 55) que nos re-dirige a los obstáculos y posibilidades del nombrar y, por ende, del lenguaje inclusivo; pero también hacia la imaginación política, cuyo límite no necesariamente es el Estado, pues "ipuede el Estado regular las fantasías sexuales de su población? Lo que nos gusta, lo que nos conmueve, lo que nos perturba está exento de la posibilidad de enseñanza" (ANGILLETTA, 2021, p. 171).

En la actualidad, el consentimiento organiza el ámbito del derecho, pero éste no agota al deseo, pues "Cuando se dice que 'sí', nunca se dice que 'sí' a todo lo que en definitiva puede hacer el otro: mentir, abandonar, engañar, descuidar. Los consensos siempre son móviles, vaporosos. La ilusión de que pueden ser totales llevaría a abolir el conflicto" (ANGILLETTA, 2021, p. 174). Para Angilletta, "no es no" se trata de una narrativa que moviliza la posibilidad de denuncia ante los delitos cometidos contra ese "no", pero en el terreno de la seducción, convergen otras formas diferenciales de seducción (ANGILLETTA, 2021, p. 175-176). Esta exposición puede resumirse en que "Para que 'no' sea 'no', 'sí' tiene que ser 'sí'” (ANGILLETTA, 2021, p. 176). Y es en el "sí" en donde se despliegan los origamis del deseo que, sin garantías, vuelan alrededor de nosotras, que tampoco somos indistintas al "espiral de significación", un concepto retomado por Marta Lamas (2021) para dibujar la confusión que ha conducido - en no pocas ocasiones - a equiparar situaciones como el acoso, con la violación e - inclusive - el feminicidio, como expuso Kohan (2019a) en la entrevista "Acostarse con un boludo no es violencia", que generó revuelo al momento de su publicación.

${ }^{3}$ En la Argentina, éstas se remontan con la agrupación Hijos e Hijas por la Identidad y la Justicia contra el Olvido y el Silencio (HIJOS) en la década de los noventa, que - en síntesis - marcaban las casas de los genocidas para indicar que no debían estar allí, sino en la cárcel. 
Por último, pero no menos importante, Angilletta aborda la prostitución, uno de los temas más problematizados para los feminismos. En su mapa de posicionamientos, en resumen, identifica en la postura abolicionista - que apela su eliminación, junto con la pornografía y el alquiler de vientre -; y la reglamentarista, que apela por incorporarla a una estructura que permita acceder a determinados derechos (ANGILLETTA, 2021, p. 146-147). El cuerpo y el trabajo son dos aristas en el corazón de su discusión: ¿se trata de libertad o de coerción?

Pensar en estos términos resulta un tanto simplista, pero - al mismo tiempo - es un modo de cuestionar qué tanta libertad y qué tanta coerción hay en otras ocupaciones, sean o no remuneradas. La trata es también una cuestión preponderante al momento de reflexionar sobre el accionar estatal en torno a quienes se encuentran en esta situación. Para Lamas (2021), la extendida imposibilidad de diferenciar que no todo comercio sexual implica trata, no es una postura que podamos atribuirle a la autora de Zona de promesas. Cinco discusiones fundamentales entre los feminismos y la política (2021), que se distingue por regalarnos preguntas, las cuales siembran - más que respuestas contundentes - otras preguntas, con la esperanza de que éstas inauguren otros pliegues temporales.

\section{Referencias}

ANGILLETTA, Florencia. Zona de promesas. Cinco discusiones fundamentales entre los feminismos y la política. Buenos Aires: Capital Intelectual, 2021.

BARRANCOS, Dora. "Sociedad femenina y politización social”. In: DÍAZ, Estela (Comp.). Feminismo y Peronismo. Reflexiones históricas y actuales de una articulación negada. Buenos Aires: Editorial de la Universidad de La Plata, 2019. p. 21-32.

DE BEAUVOIR, Simone. El segundo Sexo. Buenos Aires: Sudamericana, 2005 [1949].

HAND, David et al (Directores); DISNEY, Walt (Productor). Blancanieves y los siete enanos. [Película]. Estados Unidos. Walt Disney Productions, 1937.

HARWICZ, Ariana. Matate, Amor. Madrid: Lengua de Trapo, 2012.

KOHAN, Alexandra. "Acostarse con un boludo no es violencia". Entrevistada por Agustina Escobar. Revista Panamá, 6 de junio de 2019a. Disponible en: https://panamarevista.com/acostarse-conun-boludo-no-es-violencia/. Consultado el: 15 enero 2019.

KOHAN, Alexandra. Psicoanálisis: por una erótica contra natura. Buenos Aires: Índice Libros, 2019b.

KOHAN, Alexandra. Y Sin embargo, el amor. Elogio de lo Incierto. Buenos Aires: Paidós, 2020.

KRISTEVA, Julia. “Women's Time”. Signs, v. 7, n. 1, p. 13-35, 1981.

LAMAS, Marta. Acoso: ¿Denuncia legítima o victimización? Ciudad de México: Fondo de Cultura Económica, 2018.

LAMAS, Marta. Dolor y Política. Sentir, Pensar y Hablar desde el Feminismo. Ciudad de México: Océano, 2021.

NABOKOV, Vladimir. Lolita. Madrid: Anagrama, 2016 [1955].

POLLOCK, Griselda. Encuentros en el museo feminista virtual. Tiempo, espacio y el archivo. Madrid: Cátedra, 2010.

SARLO, Beatriz. "Los Dos Ojos de Contorno". Revista Iberoamericana, v. XLIX, n. 125, p. 797-807, 1983.

SCOT, Joan. "Unanswered Questions". The American Historical Review, v. 113, n. 5, p. 1422-1430, 2008.

María Mónica Sosa Vásquez (cronopia94@gmail.com) es antropóloga Social egresada de la Universidad Autónoma de Yucatán (UADY). Maestrante en Antropología Social de la Facultad Latinoamericana de Ciencias Sociales (FLACSO), sede Argentina. Forma parte del Laboratorio de Antropología Aplicada (FLACSO) y del Observatorio Electoral de América Latina (UBA) desde 2018, año en el cual comenzó a colaborar con la revista transfeminista PEUTEA hasta 2021. Ha publicado en la Revista Plural (Uruguay), Revista Encartes (México) y Debate Feminista (México). 
COMO CITAR ESTE ARTIGO DE ACORDO COM AS NORMAS DA REVISTA

SOSA VÁSQUEZ, María Mónica. "Alicia en su país verde: política, politización e institucionalización de los feminismos". Revista Estudos Feministas, Florianópolis, v. 30, n. 1, e81945, 2022.

\section{CONTRIBUIÇĀO DE AUTORIA}

Não se aplica.

\section{FINANCIAMENTO}

Não se aplica.

\section{CONSENTIMENTO DE USO DE IMAGEM}

Não se aplica.

\section{APROVAÇĀO DE COMITÊ DE ÉTICA EM PESQUISA}

Não se aplica.

\section{CONFLITO DE INTERESSES}

Não se aplica.

\section{LICENÇA DE USO}

Este artigo está licenciado sob a Licença Creative Commons CC-BY 4.0 International. Com essa licença você pode compartilhar, adaptar, criar para qualquer fim, desde que atribua a autoria da obra.

\section{HISTÓRICO}

Recebida em 27/05/2021

Aceita em 24/08/2021 